DOI 10. 18307/2018. 0206

(C) 2018 by Journal of Lake Sciences

\title{
典型小型水库表层沉积物重金属分布特征及生态风险”
}

\author{
匡 帅 ${ }^{1,2}$, 保琦蓓 ${ }^{3}$, 康得军 ${ }^{2}$, 申秋实 ${ }^{1,4 * *}$, 张 路 ${ }^{1,4}$, 刘 成 ${ }^{1}$, 王 恺 ${ }^{1}$ \\ (1: 中国科学院南京地理与湖泊研究所湖泊与环境国家重点实验室,南京 210008) \\ (2: 福州大学土木工程学院,福州 350116$)$ \\ (3: 宁波检验检疫科学技术研究院, 宁波 315192) \\ (4: 中国科学院中非联合研究中心,武汉 430074)
}

\begin{abstract}
摘 要: 以典型乡镇水库通济桥水库表层沉积物为研究对象, 在分析其中 $\mathrm{As} 、 \mathrm{Cd} 、 \mathrm{Cr} 、 \mathrm{Cu} 、 \mathrm{Hg} 、 \mathrm{Ni} 、 \mathrm{~Pb}$ 和 $\mathrm{Zn}$ 等有毒、有害重 金属分布特征的基础上,分析重金属来源, 评价重金属污染程度及其潜在生态危害. 结果表明: 通济桥水库表层沉积物 中, 上述 8 种重金属均存在一定程度的污染, 坝前和人库区污染物蓄积更为明显. 其中, $\mathrm{Hg}$ 和 $\mathrm{Cd}$ 的污染范围较广、污染程 度较严重. 受重金属 $\mathrm{Hg}$ 和 $\mathrm{Cd}$ 的影响, 水库表层沉积物存在中等程度的重金属生态危害风险, 其中坝前区域已处于强风 险等级. 为保障水库水体水质安全,防范重金属污染应提到当前水库管理工作的重要位置.
\end{abstract}

关键词: 表层沉积物; 重金属污染; 重金属来源; 生态风险; 小型水库;通济桥水库

\section{Distribution patterns and ecological risk assessment of heavy metal contamination in sur- face sediments deposited in a typical small sized water reservoir}

\author{
KUANG Shuai ${ }^{1,2}$, BAO Qibei ${ }^{3}$, KANG Dejun ${ }^{2}$, SHEN Qiushi ${ }^{1,4 * *}$, ZHANG Lu $^{1,4}$, LIU Cheng ${ }^{1}$ \& \\ WANG Kai ${ }^{1}$ \\ (1: State Key Laboratory of Lake Science and Environment, Nanjing Institute of Geography and Limnology, Chinese Academy \\ of Sciences, Nanjing 210008, P.R.China) \\ (2: College of Civil Engineering, Fuzhou University, Fuzhou 350116, P.R. China) \\ (3: Ningbo Inspection and Quarantine Institute of Science and Technology, Ningbo 315192, P.R.China) \\ (4: Sino-Africa Joint Research Center, Chinese Academy of Sciences, Wuhan 430074, P.R.China)
}

Abstract: Based on analysis of distribution patterns of $\mathrm{As}, \mathrm{Cd}, \mathrm{Cr}, \mathrm{Cu}, \mathrm{Hg}, \mathrm{Ni}, \mathrm{Pb}$ and $\mathrm{Zn}$ in surface sediments of the Tongjiqiao Reservoir that is a typical town reservoir, pollution degree and ecological risks were assessed by single factor index method, geoaccumulation index, potential ecological risk method and principal component analysis. The results showed that: 8 kinds of heavy metals had a certain degree of pollution in surface sediments and accumulated mainly in pre dam and southwest area. Pollution of $\mathrm{Hg}$ and $\mathrm{Cd}$ is in the broader, deeper level. Because of influence of $\mathrm{Hg}$ and $\mathrm{Cd}$, there was a moderate ecological risk of heavy metals in the surface sediments. With reference to management of reservoirs, it is of great significance to ensure the safety and management of water quality in the small sized reservoirs by putting prevention of heavy metals pollution in an important position.

Keywords: Surface sediments; heavy metals pollution; sources of heavy metal; ecological risk; small sized water reservoir; Tongjiqiao Reservoir

有毒、有害重金属是地表水体环境体系最主要的污染物之一 ${ }^{[1]}$. 通过大气干湿沉降 ${ }^{[2]}$ 、工矿业活动点源 排放 ${ }^{[3]}$ 及高地质背景含量土壤淋溶流失 ${ }^{[4]}$ 等途径, 重金属进人湖库, 然后通过悬浮颗粒物吸附沉降 ${ }^{[5]}$ 、阴阳

* 国家自然科学基金项目(51409241)、国家水体污染控制与治理科技重大专项(2013ZX07113001) 和国家重点研发 计划政府间国际科技创新合作重点专项 (2016YFE0123300) 联合资助. 2017-05-15 收稿; 2017-06-06 收修改稿. 匡帅(1993 ), 男,硕士研究生; E-mail: kssmail@163.com.

** 通信作者; E-mail: qsshen@ niglas.ac.cn. 
离子共沉淀 ${ }^{[6]}$ 和自由离子扩散 ${ }^{[7]}$ 等方式进人沉积物,使得沉积物成为重金属类物质蓄积的汇. 当外界氧化 还原条件、 $\mathrm{pH}$ 值和水动力状况等发生改变时, 吸附的重金属会释放进人水体, 沉积物成为重金属的源. 受重 金属难降解、高毒性、易富集等特点的影响,释放出来的重金属不仅会污染水体,还会通过生物富集和生物 放大作用进人食物网,进而对生态系统健康造成危害并危及人类社会工农业供水安全 ${ }^{[8-10]}$.

从国内外研究趋势来看, 以 $\mathrm{As} 、 \mathrm{Cd} 、 \mathrm{Cr} 、 \mathrm{Cu} 、 \mathrm{Hg} 、 \mathrm{Ni} 、 \mathrm{~Pb} 、 \mathrm{Zn} 8$ 种有毒有害重金属类物质在地表水环境中的 分布、溯源及潜在危害评价是近 10 多年来国内外研究的持续热点之一 ${ }^{[11-14]}$. 除自然源积累外 ${ }^{[15]}$,农业和林 业生产面源排放 ${ }^{[16]}$ 、汽车和工业活动尾气排放及沉降汇流 ${ }^{[16]}$ 、工矿业点源输出 ${ }^{[17-18]}$ 等人类活动造成的重金 属输人及蓄积是湖库等水体沉积物中该类污染物的最主要来源. 在我国内陆自然淡水水体中, 太湖、巢湖、 滇池、辽河、海河等重要河湖沉积物均受到不同程度的重金属类物质污染 ${ }^{[19-23]}$. 同样地, 人工湖库重金属污 染也已引起有关学者的高度重视 ${ }^{[24]}$. 有研究表明, 作为国家重要战略水源地的丹江口水库, 其库湾及支流 表层沉积物已处于高生态风险状态 ${ }^{[25]}$. 三峡水库 ${ }^{[26-28]}$ 、密云水库 ${ }^{[29]}$ 等重要大型水库及其周边环境水体、沉积 物或汇水区中有关重金属类物质的蓄积问题也已引起有关研究者的高度重视. 但是关于中小型水库沉积物重 金属研究报到较少, 有数据表明中小型水库占已建水库的 $95 \%$ 以上 ${ }^{[30]}$, 这些中小水库大多建于 $1950 \mathrm{~s}-$ $1970 \mathrm{~s}^{[31]}$, 经过 30 多年经济快速发展和流域水环境变迁, 水环境问题凸显 ${ }^{[32]}$. 目前, 对于沉积物重金属评价 方法有单因子污染指数法 ${ }^{[33]}$ 、地积累指数法 ${ }^{[33]}$ 、潜在生态风险指数法 ${ }^{[35]}$ 、脸谱法 ${ }^{[36]}$ 和次生相与原生相比值 法 ${ }^{[36-37]}$ 等. 其中, 地积累指数法不仅考虑了人类影响因素, 还考虑了地球化学背景值以及成岩作用对背景值 的影响, 能够比较客观的评价生态风险 ${ }^{[38]}$; 单因子指数法以背景值为基准, 能够简单有效反映重金属蓄积的 情况; 潜在生态风险指数法的优点在于既能针对单一重金属类物质进行评价, 也能对多种重金属进行综合 评价.

本研究以浙江省通济桥水库这一典型乡镇小型水库为对象 (该水库周边存在大量乡镇企业), 在分析其 表层沉积物 $\mathrm{As} 、 \mathrm{Cd} 、 \mathrm{Cr} 、 \mathrm{Cu} 、 \mathrm{Hg} 、 \mathrm{Ni} 、 \mathrm{~Pb} 、 \mathrm{Zn} 8$ 种有毒、有害重金属类物质分布规律的基础上,解析其主要来源 及污染物蓄积规律, 并利用单因子污染指数法、地积累指数法和潜在生态风险指数法对有关表层沉积物重 金属污染水平及生态风险进行评价, 为乡镇小型水库沉积物重金属生态风险管理与水环境综合治理提供科 学指导及理论依据.

\section{1 材料与方法}

\section{1 研究区域}

通济桥水库 $\left(29.420^{\circ} \sim 29.459^{\circ} \mathrm{N}, 119.802^{\circ} \sim 119.847^{\circ} \mathrm{E}\right)$ 位于我国东部沿海经济发达的浙江省金华市内, 水域面积约 $2.5 \mathrm{~km}^{2}$ 、库容约 5880 万 $\mathrm{m}^{3}$, 平均水深超过 $15 \mathrm{~m}$, 最大水深约 $35 \mathrm{~m}$, 是一座典型的乡镇小型水库. 该水库建立初期以防洪灌溉为主, 兼顾发电和渔业养殖的功能. 水库周边土地利用以农业种植和原/次生林 地为主, 在农业种植区点缀有村镇生态斑块. 1980s 以来, 通济桥水库周边村镇相继开办了各类以水晶加工 业为主的小型乡镇企业, 给水库及周边汇水区域水环境带来明显影响. 进人 21 世纪以后, 在区域环境保护 和生态文明建设的要求下, 当地政府将水库周边该类乡镇企业实施了搬迁或关停等措施, 减缓了水库水环 境保护压力. 近年来, 随着当地经济的进一步发展和城市化程度加深, 市政供水及水资源需求均明显增大, 通济桥水库功能也随之再次转变, 并被定为浦江县饮用水备用水源. 然而, 简单的水质分析与评估不足以为 水库作为备用水源地长期安全运行提供技术指导和保障. 相应地, 针对水库水环境目前存在的问题, 开展水 库底质内源及生态安全性评估, 对其综合整治与长效安全运行具有重要的意义.

\section{2 样品采集与预处理}

综合考虑通济桥水库湖岸线形态、水体污染程度、水域面积、溢流口、支流及大坝影响等因素, 在整个水 库共设 28 个采样点. 从地理方位角度, 可将通济桥水库分为坝前库区、中东部库区、北部库区、西部库区及 西南湾区等 5 个不同区域, 每个区域采样点分布见图 1. 利用重力式柱状样采样器 ( $\varnothing 8.4 \mathrm{~cm} \times \mathrm{L} 50 \mathrm{~cm}$ ) 采集 沉积物, 采用上顶法以 $1 \mathrm{~cm}$ 为间隔, 获得表层 $1 \mathrm{~cm}$ 沉积物样品, 每个点位采集 3 个平行样进行分析. 采样后 立刻将样品密封于聚乙烯袋中, 低温保存运回实验室. 沉积物鲜样在室温下风干后用玛瑙研针研磨至粉状, 并经 200 目尼龙篮网篎分后测定. 


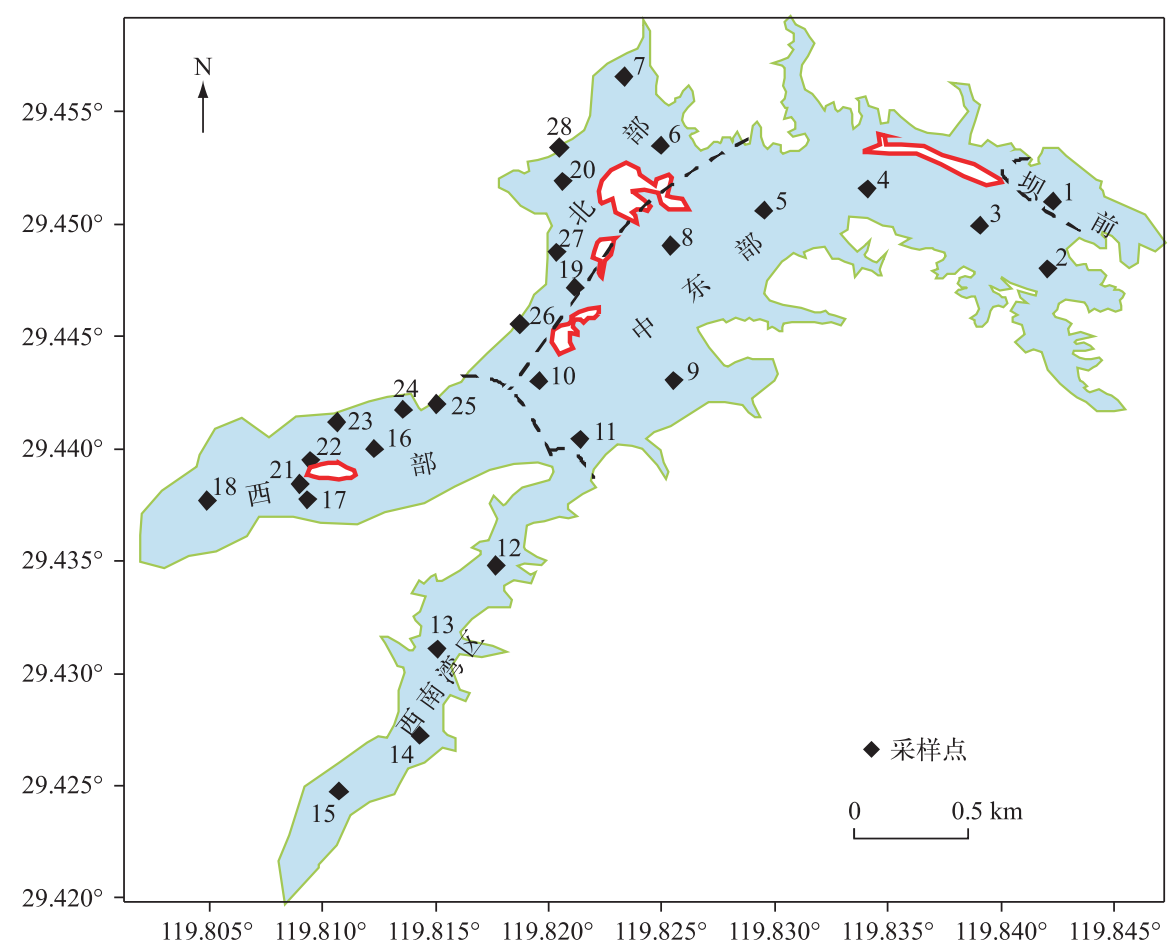

图 1 通济桥水库采样点示意

Fig.1 Sampling sites for surface sediments in the Tongjiqiao Reservoir

\section{3 样品测定方法}

对于获得的所有沉积物样品, 分析其 $\mathrm{As} 、 \mathrm{Cd} 、 \mathrm{Cr} 、 \mathrm{Cu} 、 \mathrm{Hg} 、 \mathrm{Ni} 、 \mathrm{~Pb} 、 \mathrm{Zn}$ 共 8 种有毒、有害重金属含量. 重金 属分析在湖泊与环境国家重点实验室进行, 其中, $\mathrm{As} 、 \mathrm{Cd} 、 \mathrm{Cr} 、 \mathrm{Cu} 、 \mathrm{Ni} 、 \mathrm{~Pb}$ 和 $\mathrm{Zn} 7$ 种重金属利用电感耦合等离 子体质谱仪 (ICP-MS, 7700X 型) 测定, 重金属 Hg 利用 Hydra-c 型全自动测采仪测定.

$\mathrm{Hg}$ 的分析采用美国环境保护总署颁布的“原子吸收法分析土壤和溶液中的录 (US-EPA7473 (1998)) ) 规定的有关分析方法和标准进行, $\mathrm{As} 、 \mathrm{Cd} 、 \mathrm{Cr} 、 \mathrm{Cu} 、 \mathrm{Ni} 、 \mathrm{~Pb} 、 \mathrm{Zn}$ 共 7 种重金属依据电感耦合等离子体质谱法的 有关标准( EPA Method $6020 \mathrm{a}$ (第一版, 2007 年 2 月)) 进行处理和测定.

\section{4 重金属污染评价方法}

1.4.1 地积累指数法 地积累指数法是国内外广泛应用的沉积物重金属污染评价方法之一 ${ }^{[39]}$,其计算公式为:

$$
I_{\text {geo }}=\log _{2}\left(\frac{C_{n}}{k \cdot B_{n}}\right)
$$

式中, $I_{\mathrm{geo}}$ 为地积累指数; $B_{n}$ 为当地沉积物元素 $n$ 的背景值 ${ }^{[40]}$ (As 为 $9.7 \mathrm{mg} / \mathrm{kg}, \mathrm{Cd}$ 为 $0.274 \mathrm{mg} / \mathrm{kg}, \mathrm{Cr}$ 为 60.6 $\mathrm{mg} / \mathrm{kg}, \mathrm{Cu}$ 为 $24.8 \mathrm{mg} / \mathrm{kg} 、 \mathrm{Hg}$ 为 $0.15 \mathrm{mg} / \mathrm{kg} 、 \mathrm{Ni}$ 为 $18.5 \mathrm{mg} / \mathrm{kg} 、 \mathrm{~Pb}$ 为 $42.4 \mathrm{mg} / \mathrm{kg} 、 \mathrm{Zn}$ 为 $95 \mathrm{mg} / \mathrm{kg}$ ); $C_{n}$ 为元素 $n$ 在待测沉积物中的实际含量; $k$ 为成岩作用引起的背景值波动参数, 本研究取 $1.5^{[41]}$.

根据地积累指数大小, 可对沉积物重金属污染程度进行分级, $I_{g e o}<0$, 表示无污染; 处于 $0 \sim 1$ 之间, 表示 轻度污染; 处于 1 2 之间, 表示偏中度污染; 处于 $2 \sim 3$ 之间, 表示中度污染; 处于 $3 \sim 4$ 之间, 表示偏重度污 染; 处于 $4 \sim 5$ 之间, 表示重度污染; $\geqslant 5$ 表示严重污染 ${ }^{[37]}$.

1.4.2 单因子污染指数法 重金属单因子指数 $\left(C_{f}^{i}\right)$ 是重金属的实测含量 $\left(C_{s}^{i}\right)$ 与当地背景值 $\left(C_{n}^{i}\right)$ 的比值, 表 示表层沉积物中重金属的污染状态 ${ }^{[42-43]}$, 其计算公式为:

$$
C_{f}^{i}=C_{s}^{i} / C_{n}^{i}
$$

式中, 当 $C_{f}^{i}<1$ 时, 表示无污染; $C_{f}^{i}$ 在 $1 \sim 3$ 之间, 表示轻度污染; $C_{f}^{i}$ 在 $3 \sim 6$ 之间, 表示中度污染; $C_{f}^{i} \geqslant 6$, 表示严 
重污染 ${ }^{[33]}$.

1.4.3 潜在生态风险指数法 潜在生态风险指数法 (potential ecological risk index, $R I$ ) 既可以对单项重金属 生态风险进行评价, 又可以对多项重金属综合生态风险进行评价 ${ }^{[33]}$, 其计算公式为:

(1) 单项重金属潜在生态风险指数法:

$$
E_{r}^{i}=T_{r}^{i} \cdot C_{f}^{i}
$$

式中, $E_{r}^{i}$ 表示点位 $r$ 处重金属 $i$ 的潜在生态风险系数; $T_{r}^{i}$ 重金属 $i$ 的毒性响应系数; 其中重金属毒性系数 $\mathrm{Hg}$ 为 $40, \mathrm{Cr}$ 为 $2, \mathrm{Ni}$ 为 $5, \mathrm{Cu}$ 为 $5, \mathrm{Zn}$ 为 $1, \mathrm{Cd}$ 为 $30, \mathrm{~Pb}$ 为 $5, \mathrm{As}$ 为 10 .

$E_{r}^{i}<40$, 等级为轻微; 处于 $40 \sim 80$ 之间, 等级为中等; 处于 $80 \sim 160$ 之间, 等级为强; 处于 $160 \sim 320$ 之间, 等级为很强; $\geqslant 320$, 等级为极强.

(2) 综合重金属风险指数法:

$$
R I=\sum_{i=1}^{n} E_{r}^{i}
$$

式中, $R I$ 表示综合潜在生态风险指数. $R I<150$, 等级为轻微; 处于 $150 \sim 300$ 之间, 等级为中等; 处于 $300 \sim 600$ 之间, 等级为强; $\geqslant 600$, 等级为很强.

1.4.4 数据分析及图形绘制 本研究所有相关性分析、主成分分析及聚类分析等统计分析均利用 SPSS 22.0 软件进行处理,所有图形均利用 OriginLab 8.5 和 Surfer 11 软件进行绘制.

\section{2 结果与讨论}

\section{1 表层沉积物重金属蓄积特征}

表层沉积物重金属含量统计结果 (表 1) 显示, 重金属 Zn 平均含量最高, 达到 $122.11 \mathrm{mg} / \mathrm{kg}, \mathrm{Hg}$ 的平均 含量最低,为 $0.49 \mathrm{mg} / \mathrm{kg}$. 与浙江省金奮地区土壤重金属背景值比较, $\mathrm{As} 、 \mathrm{Cd} 、 \mathrm{Cu} 、 \mathrm{Hg} 、 \mathrm{~Pb}$ 和 $\mathrm{Zn} 6$ 种重金属全 湖沉积物平均含量均超过了当地背景值. 其中 $\mathrm{As} 、 \mathrm{Cd}$ 和 $\mathrm{Hg}$ 等重金属局部地区含量超过了二级土壤环境质 量标准,这 3 种重金属平均含量分别达到背景值的 2.16、2.70 和 3.29 倍.

从变异系数来看, 8 种重金属空间分布差异较大. 其中, $\mathrm{Hg}$ 和 $\mathrm{Cd}$ 的空间异质性最大,变异系数分别达到 $67.07 \%$ 和 $60.02 \%$,其余重金属变异系数也均在 $30 \%$ 以上.

表 1 通济桥水库表层沉积物重金属含量统计结果

Tab.1 Statistical results of heavy metals in the surface sediments

\begin{tabular}{lrrrrrrrr}
\hline 统计参数 & $\mathrm{As}$ & $\mathrm{Cd}$ & $\mathrm{Cr}$ & $\mathrm{Cu}$ & $\mathrm{Hg}$ & $\mathrm{Ni}$ & $\mathrm{Pb}$ & $\mathrm{Zn}$ \\
\hline 均值 $/(\mathrm{mg} / \mathrm{kg})$ & 21.80 & 0.73 & 58.55 & 25.70 & 0.49 & 16.06 & 55.40 & 122.11 \\
最大值 $/(\mathrm{mg} / \mathrm{kg})$ & 43.78 & 1.69 & 126.00 & 36.20 & 1.58 & 22.88 & 113.30 & 183.38 \\
最小值 $/(\mathrm{mg} / \mathrm{kg})$ & 6.10 & 0.09 & 13.17 & 4.72 & 0.21 & 5.19 & 17.13 & 50.94 \\
变异系数 $/ \%$ & 44.14 & 60.02 & 49.39 & 32.84 & 67.07 & 33.77 & 44.63 & 33.46 \\
背景值 $/(\mathrm{mg} / \mathrm{kg})$ & 9.70 & 0.27 & 60.60 & 24.80 & 0.15 & 18.50 & 42.40 & 95.00 \\
土壤环境一级标准(碱性 $) /(\mathrm{mg} / \mathrm{kg})$ & 15.00 & 0.20 & 90.00 & 35.00 & 0.15 & 40.00 & 35.00 & 100.00 \\
土壤环境二级标准(碱性 $) /(\mathrm{mg} / \mathrm{kg})$ & 20.00 & 0.60 & 350.00 & 100.00 & 1.00 & 60.00 & 350.00 & 300.00 \\
均值/背景值 & 2.17 & 2.70 & 0.97 & 1.04 & 3.29 & 0.87 & 1.31 & 1.29 \\
\hline
\end{tabular}

从表层沉积物重金属空间分布来看(图 2),8种重金属空间异质性较大. As、 $\mathrm{Cd} 、 \mathrm{Cr} 、 \mathrm{Hg} 、 \mathrm{~Pb} 5$ 种重金属 含量在不同湖区表层沉积物含量区别较大. 总体而言, $\mathrm{As} 、 \mathrm{Cd} 、 \mathrm{Cr}$ 在坝前区域含量最高, 西南湾区次之, 中东 部含量进一步下降, 西部及北部含量最低; $\mathrm{Pb}$ 含量相对较高区域集中在西南湾区, 中部和东部湖区及西部湖 区含量较小, 北部和西北部湖区含量最低. $\mathrm{Hg}$ 在坝前、西部湖湾和北部湖区零星区域含量相对较高, 其它湖 区表层沉积物 $\mathrm{Hg}$ 含量较低. 水库表层沉积物 $\mathrm{Cu} 、 \mathrm{Ni} 、 \mathrm{Zn} 3$ 种重金属分布相似,坝前、中东部湖区以及西南湾 区含量相对较高, 西部和北部湖区含量较低. 坝前沉积物重金属含量较高, 显示人库污染物随流场及水动力 条件迁移并在坝前沉降, 并造成一定程度的污染物蓄积; 西南湖湾区沉积物重金属含量较高, 可能与该湾区 周边村镇加工制造业发展有关. 

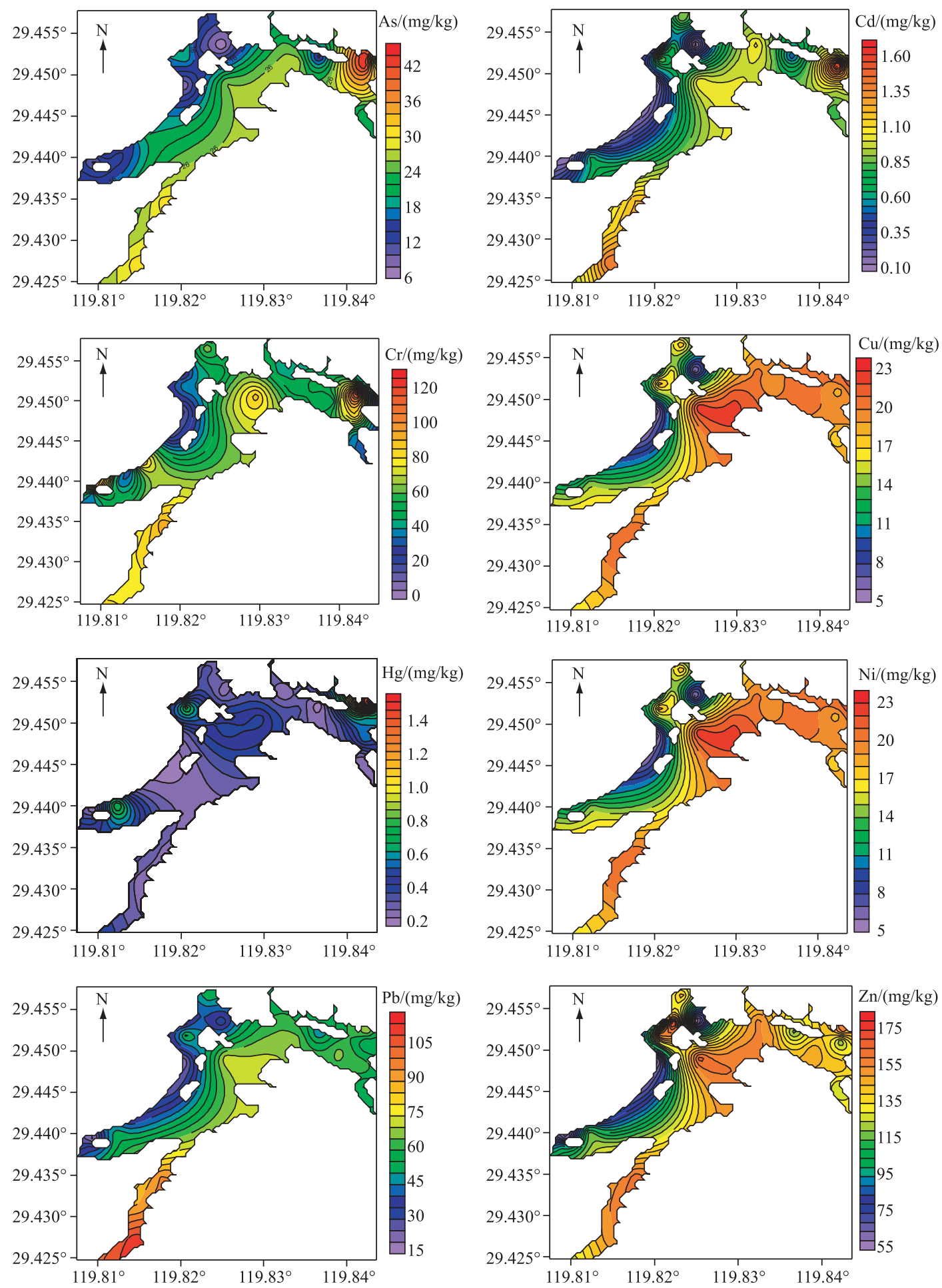

图 2 通济桥水库表层沉积物重金属含量分布

Fig.2 Distributions of heavy metals in surface sediments of the Tongiiqiao Reservoir 


\section{2 表层沉积物重金属空间分布归趋}

采用欧式平方距离, 通过 $Q$ 型聚类 - 最远邻元素法对数据进行聚类分析. 采用距离 10 分类 (图 3) 可以 分为 I 、II、III三类. I 类表示以中东部为主、重金属含量相对较低的区域; II 类表示以坝前以及西南湾区为 代表的重金属高含量区域; III类则表示以西部、北部库区为主、重金属含量最低的区域.

\section{3 通济桥水库表层沉积物重金属来源分析}

相关性良好的污染物, 可能具有相似来源 ${ }^{[46]}$. 将通济桥水库不同点位表层沉积物重金属含量分析结果 进行相关性分析可知 (表 2): $\mathrm{As} 、 \mathrm{Cd} 、 \mathrm{Cu} 、 \mathrm{Ni} 、 \mathrm{~Pb} 、 \mathrm{Zn} 6$ 种重金属两两之间呈显著正相关, $\mathrm{Cr}$ 与 $\mathrm{As} 、 \mathrm{Cd}$ 之间均 呈显著正相关 $(P<0.01, r=0.450 ; P<0.01, r=0.444), A s$ 与 $\mathrm{Hg}$ 之间也呈显著正相关 $(P<0.05, r=0.484)$. 说明 这些重金属之间存在相似的来源、迁移和沉积过程, 同时也反映了这些重金属在表层沉积物中含量比具有 相对的稳定性.

表 2 表层沉积物重金属间相关系数矩阵(样本量 $n=28$ )

Tab.2 Correlation coefficients among the concentrations of the heavy metals in surface sediments

\begin{tabular}{cllllllll}
\hline 相关系数 & $\mathrm{As}$ & $\mathrm{Cd}$ & $\mathrm{Cr}$ & $\mathrm{Cu}$ & $\mathrm{Hg}$ & $\mathrm{Ni}$ & $\mathrm{Pb}$ & $\mathrm{Zn}$ \\
\hline $\mathrm{As}$ & 1 & & & & & & & \\
$\mathrm{Cd}$ & $0.763^{* *}$ & 1 & & & & & \\
$\mathrm{Cr}$ & $0.450^{*}$ & $0.444^{*}$ & 1 & & & & \\
$\mathrm{Cu}$ & $0.552^{* *}$ & $0.797^{* *}$ & 0.198 & 1 & & & \\
$\mathrm{Hg}$ & $0.484^{* *}$ & $0.307^{* *}$ & 0 & 0.349 & 1 & & 1 \\
$\mathrm{Ni}$ & $0.600^{* *}$ & $0.817^{* *}$ & 0.288 & $0.912^{* * *}$ & 0.327 & 1 & \\
$\mathrm{~Pb}$ & $0.626^{* *}$ & $0.780^{* *}$ & 0.361 & $0.700^{* *}$ & 0.161 & $0.678^{* * *}$ & 1 \\
$\mathrm{Zn}$ & $0.549^{* *}$ & $0.818^{* *}$ & 0.144 & $0.959^{* *}$ & 0.344 & $0.905^{* *}$ & $0.727^{* * *}$ & 1 \\
\hline
\end{tabular}

* 表示在 $P<0.05$ 水平上显著相关, ** 表示在 $P<0.01$ 水平上显著相关.

为进一步对各重金属来源进行分析,利用主成分分析法对通济桥水库表层沉积物 8 种重金属进行因子 分析 (图 3), 经方差最大正交旋转后, 提取到了 2 个特征根大于 1 的主成分, 其中前 2 个主成分解释了总方 差的 $76.97 \%$, 已可满足因子分析的要求. 主成分 1 解释了总方差变量的 $54.01 \%$, 其中, $\mathrm{As} 、 \mathrm{Cd} 、 \mathrm{Cu} 、 \mathrm{Hg} 、 \mathrm{Ni} 、 \mathrm{~Pb}$ 和 Zn 7 种重金属在该主成分上具有较高的荷载.一般而言,在没有矿业开发的区域中,环境中出现明显蓄积 的几类重金属具有以下主要来源: $\mathrm{Hg}$ 主要来自于燃煤废气、汽车尾气排放等活动 ${ }^{[47]}, \mathrm{Cd} 、 \mathrm{As} 、 \mathrm{Ni} 、 \mathrm{Cu}$ 等与工 农业活动密切相关 ${ }^{[48]}$, 而 $\mathrm{Pb}$ 和 $\mathrm{Zn}$ 则主要来自工业废气或废水排放 ${ }^{[49]}$. 这类污染物通过大气干湿沉降及地 表水径流进人环境水体, 最终进人湖库及其它类型沉积物并得到蓄积. 人造水晶与一般玻璃的区别在于其 高含 $\mathrm{Pb}$ 量, $\mathrm{Pb}$ 含量达到 $24 \%$. 同时浦江县水晶加工原料包括 $\mathrm{K} 9$ 玻璃, 该玻璃料含有一定含量的氧化砷 $\left(\mathrm{As}_{2} \mathrm{O}_{3}\right)$. 水晶在切割、滚磨、打孔、抛光等加工过程中也会产生大量含重金属的废水,许多小工作坊未经处 理便排放进外界水体. 2.1 节研究可知, 重金属在西南湾区和坝前蓄积比较严重. 考虑到西南湾区周边大量 的小加工坊以及流场、水动力条件的影响, 重金属可能是在西南湾区大量输人导致一部分重金属在此大量 蓄积, 同时一部分重金属受水利条件的影响迁移至坝前区域. 因此, 可以认为主成分 1 代表的是人类工业活 动来源的重金属,工业污染输人是通济桥水库表层沉积物重金属污染物的第一主要来源.

主成分 2 解释了总方差变量的 $22.90 \%$, 金属 $\mathrm{Cr}$ 在该主成分上具有最高的荷载, $\mathrm{As} 、 \mathrm{Cd}$ 和 $\mathrm{Pb}$ 在该主成 分上的载荷也较高. 在本研究中, 通济桥水库不同湖区表层沉积物中 $\mathrm{Cr}$ 含量总体偏低, 但空间异质性较大 $(C V$ 达到 $49.39 \%$ ), 在坝前和西南湾区, 表层沉积物 $\mathrm{Cr}$ 含量均明显高于环境背景值, 同时在西部存在零星蓄 积. As、Cd 和 Pb 3 种金属也表现出类似的空间分布趋势及积累特征. 相关性分析也表明, Cr 与 $\mathrm{As} 、 \mathrm{Cd}$ 均呈 显著正相关 $(P<0.05), \mathrm{Pb}$ 与 $\mathrm{As} 、 \mathrm{Cd}$ 也均呈显著正相关 $(P<0.01)$. 除去工业源外, 农业面源污染输人往往是 湖库水体和沉积物 As、Cd、Cr 等重金属的重要来源 ${ }^{[48]}$. 因此, 可以认为主成分 2 代表的是来自人类农业源的 重金属,农业面源输人是通济桥水库表层沉积物重金属污染物的第二主要来源.

\section{4 表层沉积物重金属生态风险评估}

2.4.1 重金属单因子污染指数 $\left(C_{f}^{i}\right)$ 单因子污染指数是反映沉积物受某一污染物污染程度大小的重要衡量 

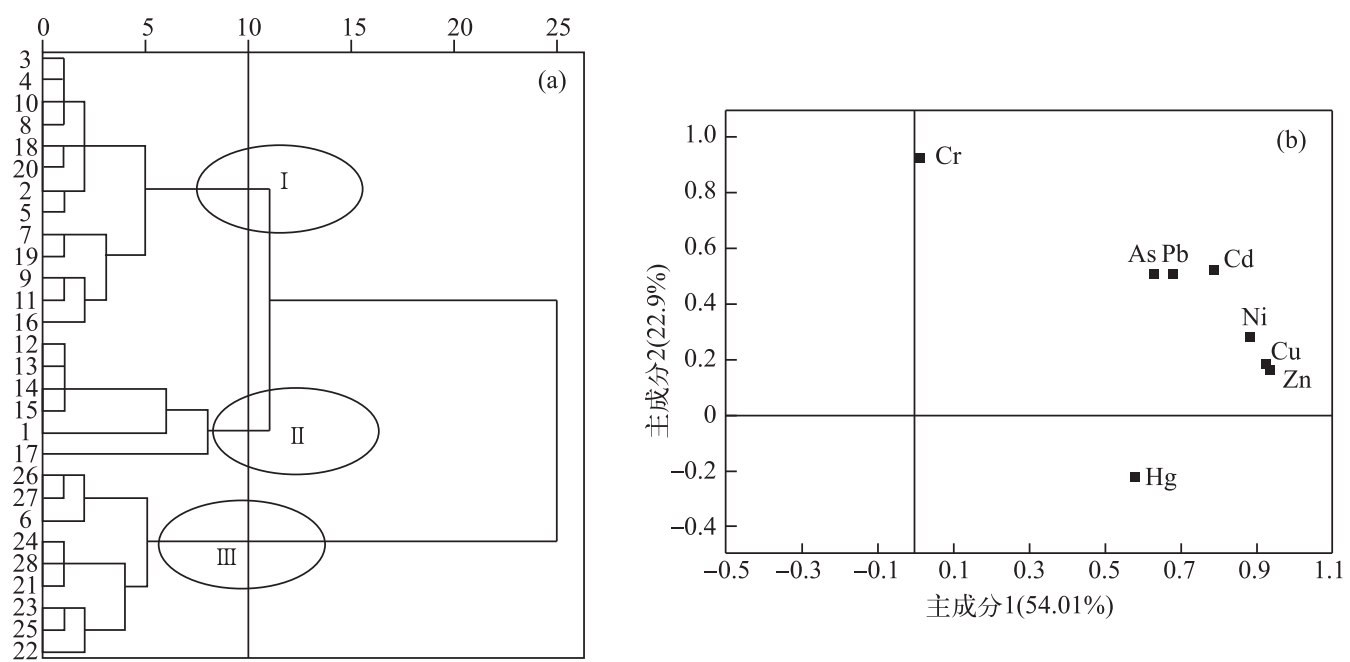

图 3 表层沉积物取样点位聚类分析 (a)（ I 类代表中东部为主的区域，

II 类表示坝前区域以及西南湾区, III类代表西部、北部库区)和主成分荷载图 (b)

Fig.3 Dendrogram of cluster of sampling sites(a) ( I stands for central and eastern area,

II stands for pre dam area and the southwest bay area, III stands for western and northern area) and loading values of the principal components $(b)$

标准, 依据污染指数大小, 可以划分出沉积物受相应物质污染的等级. 结果表明 (表 3), As、Cd、Cr、Cu、 $\mathrm{Hg} 、$ $\mathrm{Ni} 、 \mathrm{~Pb} 、 \mathrm{Zn} 8$ 种有毒、有害重金属在水库表层沉积物中均出现程度不一的富集和污染现象, 其平均污染指数 大小顺序为 $\mathrm{Hg}>\mathrm{Cd}>\mathrm{As}>\mathrm{Pb}>\mathrm{Zn}>\mathrm{Cu}>\mathrm{Cr}>\mathrm{Ni}$. 重金属 $\mathrm{Hg}$ 的平均污染指数达到 3.07, 全湖沉积物平均处于中度 $\mathrm{Hg}$ 污染状态; 其次为 $\mathrm{As} 、 \mathrm{Cd} 、 \mathrm{Cu} 、 \mathrm{~Pb}$ 和 $\mathrm{Zn}$ 的全湖平均污染指数在 $1.04 \sim 2.65$ 之间, 沉积物平均处于轻度 $\mathrm{As}$ 、 $\mathrm{Cd} 、 \mathrm{Cu} 、 \mathrm{~Pb} 、 \mathrm{Zn}$ 污染状态. 重金属 $\mathrm{Cr}$ 和 $\mathrm{Ni}$ 的全湖平均污染指数分别为 0.97 和 0.87 , 沉积物平均处于无 $\mathrm{Cr} 、 \mathrm{Ni}$ 污染状态. 然而, 全湖沉积物各种金属污染指数变异系数较大, 不同湖区沉积物受重金属污染程度空间异质 性较强. $\mathrm{Hg} 、 \mathrm{Cd}$ 的污染指数变异系数均在 $60 \%$ 以上; $\mathrm{Ni} 、 \mathrm{Zn}$ 和 $\mathrm{Cu}$ 的污染指数变异系数最小, 也都在 $30 \%$ 以 上. 即使全湖沉积物总体平均不受 $\mathrm{Cr}$ 和 $\mathrm{Ni}$ 污染, 但坝前和西南湖湾部分区域沉积物已处于轻度 $\mathrm{Cr} 、 \mathrm{Ni}$ 污染 状态.

2.4.2 地积累指数 ( $\left.I_{\mathrm{geo}}\right)$ 地积累指数法能够比较客观地评价生态风险, 通过对通济桥水库表层沉积物重金 属地积累指数的计算, 重金属 $\mathrm{Hg}$ 的 $I_{\mathrm{geo}}$ 最大 (为 0.92 ), $\mathrm{Ni}$ 的 $I_{\mathrm{geo}}$ 最小 (为-0.87). 8 种重金属 $I_{\mathrm{geo}}$ 大小顺序为 $\mathrm{Hg}>\mathrm{As}>\mathrm{Cd}>\mathrm{Zn}>\mathrm{Pb}>\mathrm{Cu}>\mathrm{Cr}>\mathrm{Ni}$.

由 $I_{\mathrm{geo}}$ 分布 (图 4) 可知, 除 $\mathrm{Ni} 、 \mathrm{Cu}$ 外, 其它 6 种重金属存在一定区域的污染. 从 $I_{\mathrm{geo}}$ 分布来看, 受到 $\mathrm{Zn}$ 、 As、Cd 和 $\mathrm{Hg} 4$ 种重金属污染的点位占全部采样点的 $50 \%$ 及以上, 其中 $\mathrm{Hg}$ 污染的点位占比达到 $92.9 \%$, Cd、 As 均在 $60 \%$ 以上. 因此, 8 种重金属中 $\mathrm{Hg}$ 的污染范围最大, 其次为 $\mathrm{Cd} 、 \mathrm{As}$. 从出现的污染等级来看, $\mathrm{Cd} 、 \mathrm{Hg}$ 、 As 3 种重金属均呈现中度污染. 在分析的 8 种重金属中, $\mathrm{Hg}$ 和 $\mathrm{Cd}$ 污染范围较广、程度较深.

此外对同一采样点 8 种重金属 $I_{\mathrm{geo}}$ 进行比较, 发现 17、1 号采样点 $I_{\mathrm{geo}}$ 最高. 这与前面分析结果类似.

经计算, 8 种重金属 $I_{g e o}$ 变异系数大小顺序为 $\mathrm{Cd}>\mathrm{Pb}>\mathrm{Zn}>\mathrm{As}>\mathrm{Cu}>\mathrm{Cr}>\mathrm{Hg}>\mathrm{Ni}$. 其中重金属 $\mathrm{Cd}$ 和 $\mathrm{Pb}$ 的变 异系数最大, 分别达到 $298.40 \%$ 和 $202.32 \%$, 表明这 2 种重金属 $I_{\mathrm{gee}}$ 的空间差异明显大于其它重金属. 其次重 金属 $\mathrm{Zn} 、 \mathrm{As} 、 \mathrm{Cu}$ 和 $\mathrm{Cr}$ 变异系数在 $100 \% \sim 200 \%$ 之间, $\mathrm{Hg}$ 和 Ni $I_{g \mathrm{geo}}$ 的变异系数最小, 但也在 $70 \%$ 以上. 说明通 济桥水库表层沉积物重金属 $I_{\mathrm{geo}}$ 均存在较大空间差异, 区域背景差异影响很大.

2.4.3 潜在生态风险评价 生态风险指数法无论是对单项重金属生态风险进行评价, 还对多项重金属综合生 态风险进行评价都具有重要的指导意义. 整体而言, 通济桥水库表层沉积物重金属平均生态风险指数为 234.92 , 全湖沉积物整体处于中等潜在生态风险等级. 从重金属综合潜在风险指数空间分布 (图 5) 来看, 坝 
表 3 通济桥水库表层沉积物重金属单因子污染指数

Tab.3 Single factor index ( $C_{r}^{i}$ value) of heavy metals in the surface sediments of the Tongjiqiao Reservoir

\begin{tabular}{|c|c|c|c|c|c|c|c|c|}
\hline 采样点 & As & $\mathrm{Cd}$ & $\mathrm{Cr}$ & $\mathrm{Cu}$ & $\mathrm{Hg}$ & $\mathrm{Ni}$ & $\mathrm{Pb}$ & $\mathrm{Zn}$ \\
\hline 1 & 4.50 & 6.16 & 2.08 & 1.07 & 4.65 & 1.00 & 1.15 & 1.26 \\
\hline 2 & 3.31 & 3.50 & 1.37 & 1.25 & 3.98 & 1.08 & 1.51 & 1.54 \\
\hline 3 & 3.02 & 3.44 & 0.74 & 1.26 & 2.55 & 1.11 & 1.57 & 1.59 \\
\hline 4 & 2.85 & 3.35 & 0.76 & 1.20 & 2.50 & 1.04 & 1.57 & 1.59 \\
\hline 5 & 2.60 & 3.52 & 1.45 & 1.25 & 3.49 & 1.18 & 1.60 & 1.61 \\
\hline 6 & 0.62 & 0.32 & 0.75 & 0.19 & 1.83 & 0.28 & 0.72 & 0.54 \\
\hline 7 & 1.45 & 3.32 & 1.07 & 1.42 & 2.44 & 0.98 & 1.26 & 1.51 \\
\hline 8 & 2.68 & 3.86 & 1.04 & 1.37 & 3.50 & 1.24 & 1.73 & 1.77 \\
\hline 9 & 2.18 & 3.01 & 0.62 & 1.07 & 1.87 & 0.95 & 1.16 & 1.32 \\
\hline 10 & 2.55 & 3.91 & 0.72 & 1.29 & 1.68 & 1.09 & 1.48 & 1.65 \\
\hline 11 & 1.31 & 1.80 & 0.86 & 1.05 & 1.41 & 1.10 & 1.06 & 1.24 \\
\hline 12 & 3.17 & 4.37 & 1.53 & 1.26 & 1.96 & 1.11 & 2.25 & 1.70 \\
\hline 13 & 2.75 & 4.15 & 1.37 & 1.21 & 1.84 & 1.12 & 2.15 & 1.65 \\
\hline 14 & 3.17 & 5.10 & 1.25 & 1.29 & 2.06 & 1.00 & 2.67 & 1.60 \\
\hline 15 & 2.71 & 3.49 & 1.34 & 1.21 & 2.92 & 0.88 & 2.48 & 1.36 \\
\hline 16 & 1.33 & 2.44 & 0.58 & 1.06 & 5.59 & 0.79 & 1.27 & 1.25 \\
\hline 17 & 4.51 & 3.59 & 0.76 & 1.32 & 10.55 & 1.13 & 1.65 & 1.68 \\
\hline 18 & 2.31 & 3.27 & 0.74 & 1.29 & 5.16 & 1.16 & 1.30 & 1.55 \\
\hline 19 & 1.23 & 2.65 & 0.66 & 1.46 & 3.09 & 0.91 & 0.99 & 1.93 \\
\hline 20 & 1.98 & 3.28 & 0.68 & 1.24 & 5.27 & 1.02 & 1.35 & 1.68 \\
\hline 21 & 1.33 & 0.98 & 0.63 & 0.96 & 2.69 & 0.78 & 0.85 & 1.02 \\
\hline 22 & 0.94 & 0.61 & 1.65 & 0.52 & 1.68 & 0.66 & 0.40 & 0.59 \\
\hline 23 & 2.13 & 0.99 & 1.63 & 0.71 & 3.25 & 0.47 & 1.06 & 0.78 \\
\hline 24 & 1.42 & 0.85 & 0.40 & 0.71 & 2.54 & 0.55 & 0.79 & 0.72 \\
\hline 25 & 2.06 & 0.67 & 1.51 & 0.74 & 1.83 & 0.53 & 0.78 & 0.75 \\
\hline 26 & 1.78 & 0.53 & 0.28 & 0.55 & 1.37 & 0.33 & 0.58 & 0.69 \\
\hline 27 & 0.83 & 0.69 & 0.22 & 0.36 & 2.13 & 0.29 & 0.48 & 0.60 \\
\hline 28 & 2.12 & 0.42 & 0.35 & 0.70 & 2.14 & 0.56 & 0.71 & 0.82 \\
\hline 平均值 & 2.24 & 2.65 & 0.97 & 1.04 & 3.07 & 0.87 & 1.31 & 1.29 \\
\hline 最大值 & 4.51 & 6.16 & 2.08 & 1.46 & 10.55 & 1.24 & 2.67 & 1.93 \\
\hline 最小值 & 0.62 & 0.32 & 0.22 & 0.19 & 1.37 & 0.28 & 0.40 & 0.54 \\
\hline 变异系数/\% & 44.14 & 60.02 & 49.39 & 32.84 & 61.46 & 33.77 & 44.63 & 33.46 \\
\hline
\end{tabular}

前最高, 西南湖区、中部湖区以及西南湖湾次之, 西部及西北部最低. 除坝前区域处于强生态风险等级, 其它 大部分区域处于轻微或中等潜在生态风险. 该水库表层沉积物重金属综合潜在生态风险变异系数为 $46.1 \%$, 说明潜在生态风险指数分布同样受到空间差异的影响.

单项重金属潜在生态风险指数大小顺序为 $\mathrm{Hg}>\mathrm{Cd}>\mathrm{As}>\mathrm{Pb}>\mathrm{Cu}>\mathrm{Ni}>\mathrm{Cr}>\mathrm{Zn}$, 除 $\mathrm{Hg}$ 处于强潜在生态风险 等级、Cd 处于中等潜在生态风险等级外,其它重金属均称处于轻微潜在生态风险等级. 说明沉积物中 $\mathrm{Hg}$ 、 $\mathrm{Cd}$ 的污染程度较其它重金属高,这与前面分析结果类似.

进一步分析不同重金属对综合潜在生态风险的贡献, 8 种重金属对综合潜在生态风险贡献的大小顺序 为 $\mathrm{Hg}>\mathrm{Cd}>\mathrm{As}>\mathrm{Pb}>\mathrm{Cu}>\mathrm{Ni}>\mathrm{Cr}>\mathrm{Zn}$, 重金属 $\mathrm{Hg}$ 、 Cd 贡献最大, 分别达到 50.32\%、32.60\% ; 其次是 $\mathrm{As}$, 为 9.19\%; 其余 5 种重金属贡献率仅为 $7.89 \%$. 其中 $\mathrm{Hg}$ 含量最低, 但是潜在综合风险贡献最大, 而 $\mathrm{Zn}$ 含量最大但是其 贡献度最小. 这主要因为 $\mathrm{Hg}$ 毒性系数最大, 而 $\mathrm{Zn}$ 毒性系数最小. 重金属 $\mathrm{Hg}$ 和 $\mathrm{Cd}$ 对潜在生态风险指数的 贡献达到 $80 \%$ 以上. 因此, 该水库表层沉积物重金属综合潜在生态风险主要取决于 $\mathrm{Hg}$ 和 $\mathrm{Cd}$ 的存在. 这与赵 


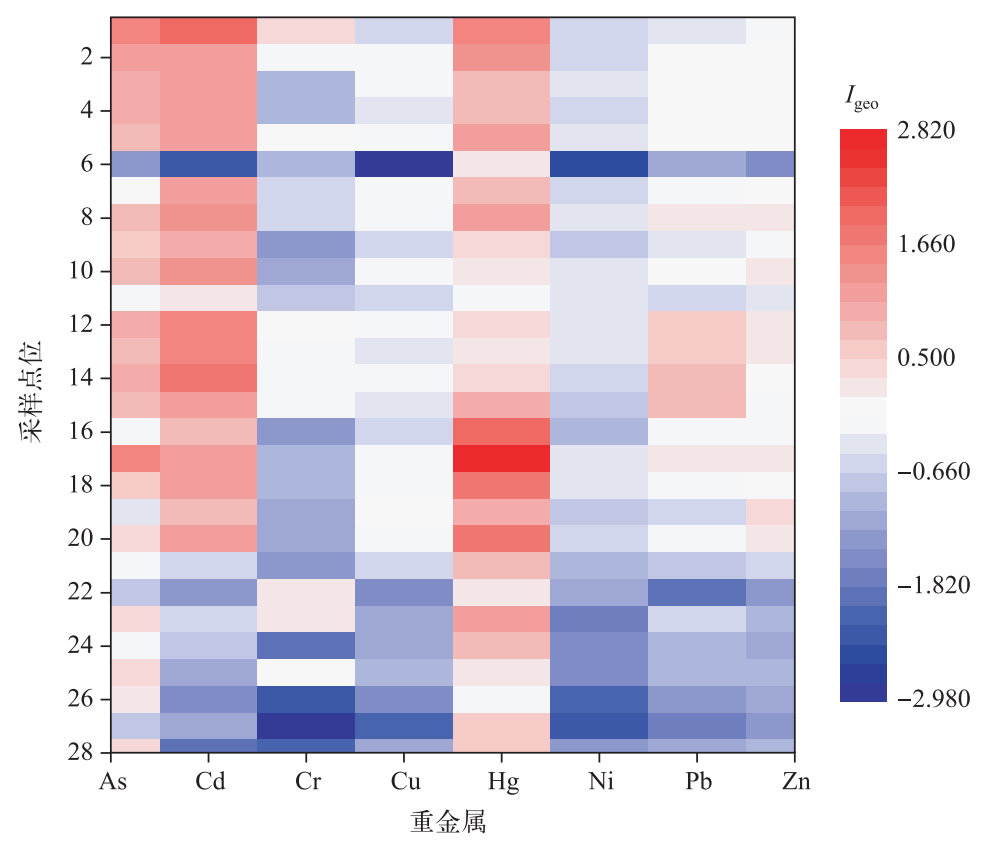

图 4 通济桥水库表层沉积物重金属地积累指数分布

Fig.4 Geoaccumulation index of heavy metals in the surface sediment of the Tongjiqiao Reservoir

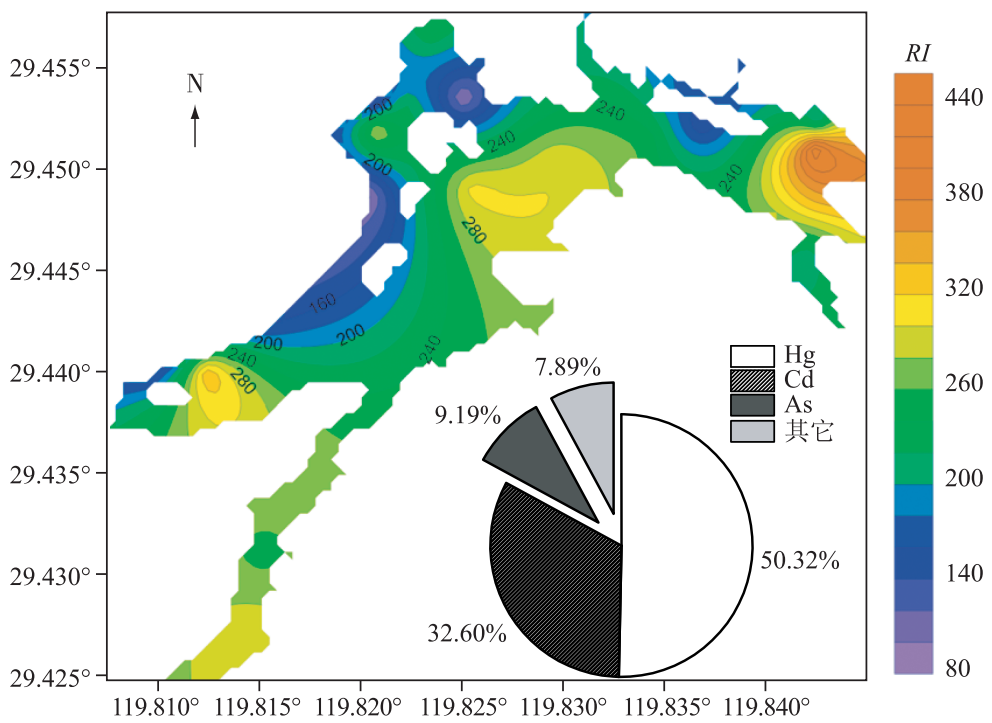

图 5 表层沉积物重金属综合潜在生态风险指数及重金属对其的贡献率

Fig.5 Potential ecological risk of heavy metals and contribution rates of heavy metals to the potential ecological risk indices

世民等 ${ }^{[50]}$ 对滇池的研究相似, 认为滇池及其河口沉积物潜在生态风险贡献最大的为 $\mathrm{Cd}$ 和 $\mathrm{Hg}$, 最小的则是 $\mathrm{Zn}$ 和 $\mathrm{Cr}$. 


\section{3 结论}

通过对典型乡镇小型水库通济桥水库全湖不同区域表层沉积物 $\mathrm{As} 、 \mathrm{Cd} 、 \mathrm{Cr} 、 \mathrm{Cu} 、 \mathrm{Hg} 、 \mathrm{Ni} 、 \mathrm{~Pb} 、 \mathrm{Zn}$ 共 8 种有 毒、有害重金属蓄积状态及空间分布的研究可以看出,对于这样一个位于工农业生产活跃、经济发展水平较 高区域的乡镇小型水库, 其表层沉积物出现明显的重金属蓄积情况, $\mathrm{As} 、 \mathrm{Cd} 、 \mathrm{Cu} 、 \mathrm{Hg} 、 \mathrm{~Pb} 、 \mathrm{Zn} 6$ 种重金属在全 湖平均含量均超过当地背景值, 其中, As、Cd 和 $\mathrm{Hg}$ 平均含量分别为 $21.80 、 0.73 、 0.494 \mathrm{mg} / \mathrm{kg}$, 分别达到背景 值的 2.16、2.70 和 3.29 倍. 地积累指数分析表明, $\mathrm{Hg}$ 和 $\mathrm{Cd}$ 是通济桥水库表层沉积物中污染范围最大、污染 程度最高的 2 种重金属. 从空间分布来看, 坝前和西南湖湾入湖区域重金属污染物明显较多, 是各重金属主 要的汇集区域. 应用主成分分析法对污染物来源进行归趋分析, 主成分 1 解释了总方差变量的 $54.01 \%$, 主成 分 2 解释了总方差变量的 $22.9 \%$, 2 个主成分解释了总方差的 $76.91 \%$. 综合分析表明工业污染输人是通济 桥水库表层沉积物重金属污染物的第一主要来源, 农业面源输人对其表层沉积物重金属污染物有重要贡献. 潜在生态风险分析表明, 通济桥水库表层沉积物重金属平均生态风险指数为 234.92 , 全湖沉积物重金属危 害处于中等潜在生态风险等级,其中坝前区域处于强生态风险等级,表层沉积物重金属已对其生态安全构 成潜在危害. 因此, 对坝前等主要受污染区域沉积物开展综合治理与处置, 对保障典型乡镇小型水库通济桥 水库的水质安全和生态健康具有重要意义.

\section{4 参考文献}

[ 1 ] Singh UK, Kumar B. Pathways of heavy metals contamination and associated human health risk in Ajay River basin, India. Chemosphere, 2017, 174: 183-199.

[ 2 ] Tang J, Han WZ, Li N et al. Multivariate analysis of heavy metal element concentrations in atmospheric deposition in Harbin City, Northeast China. Spectroscopy and Spectral Analysis, 2011, 31(11) : 3087-3091. [汤洁, 韩维峥, 李娜等. 哈 尔滨市城区大气重金属沉降特征和来源研究. 光谱学与光谱分析, 2011, 31(11): 3087-3091.]

[ 3 ] Li XH, Tang ZL, Chu FY. Analysis on speciation and transportation of heavy metals in water and sediment in baiyin mine. Earth and Environment, 2008, 36(3) : 218-224. [李小虎, 汤中立, 初风友. 白银矿山水体和沉积物中重金属及其 化学形态分布特征. 地球与环境, 2008, 36(3) : 218-224.]

[ 4 ] Liao BH, Zeng M, Guo ZH et al. Release characteristics of Cd, Cu and Zn from the natural and contaminated red soils under simulated acid rain. Environmental Chemistry, 2009, 28(3): 343-349. [廖柏寒, 曾敏, 郭朝晖等. 模拟酸雨下自 然红壤与污染红壤中 $\mathrm{Cd}, \mathrm{Cu}, \mathrm{Zn}$ 的释放特征. 环境化学, 2009, 28(3) : 343-349.]

[ 5 ] Lu YZ, Yan BX. Competitive adsorption of heavy metals on songhua river sediments and effect of pH. Research of Environmental Sciences, 2010, 23(1):20-25. [ 路永正, 阎百兴. 重金属在松花江沉积物中的竞争吸附行为及 $\mathrm{pH}$ 的影响. 环境科学研究, 2010, 23(1): 20-25.]

[ 6 ] Liu Y, Zhang CJ, Lei GL et al. Migration and enrichment characteristics of heavy metals in surface sediments of the midreach of Wanchuan River in Lanzhou City. Acta Sedimentologica Sinica, 2008, 26(5):844-849. [刘艳, 张成君, 雷国 良等. 兰州市宛川河中段表层沉积物中重金属元素迁移富集特征. 沉积学报, 2008, 26(5): 844-849.]

[ 7 ] Liu EF, Shen J, Wang JJ et al. Chemical forms of the heavy metals in surface sediment from nansihu lake and their diffusion flux at the sediment-water interface. Environmental Chemistry, 2010, 29(5): 870-874. [刘恩峰, 沈吉, 王建军等. 南四湖表层沉积物重金属的赋存形态及底部界面扩散通量的估算. 环境化学, 2010, 29(5) : 870-874.]

[ 8 ] Vinodhini R, Narayanan M. Bioaccumulation of heavy metals in organs of fresh water fish Cyprinus carpio (Common carp). International Journal of Environmental Science and Technology, 2008, 5(2): 179-182.

[ 9 ] Zhang L, Wang W. Size-dependence of the potential for metal biomagnification in early life stages of marine fish. Environmental Toxicology and Chemistry, 2007, 26(4): 787-794.

[10] Bocher P, Caurant F, Miramand P et al. Influence of the diet on the bioaccumulation of heavy metals in zooplankton-eating petrels at Kerguelen archipelago, Southern Indian Ocean. Polar Biology, 2003, 26(12) : 759-767.

[11] Yang Z, Wang Y, Shen Z et al. Distribution and speciation of heavy metals in sediments from the mainstream, tributaries, and lakes of the Yangtze River catchment of Wuhan, China. Journal of Hazardous Materials, 2009, 166 (2/3): 1186-1194. 
[12] Zhang W, Jin X, Di Z et al. Heavy metals in surface sediments of the shallow lakes in eastern China: Their relations with environmental factors and anthropogenic activities. Environmental Science and Pollution Research International, 2016, 23 (24) : 22537-25364.

[13] Zhou XH, Liu LM, Chen X et al. Heavy metals distribution characteristics and ecological risk evaluation in surface sediments of dammed Jinshan Lake. Environmental Science, 2014, 35(11): 4127-4134. [ 周晓红, 刘龙梅, 陈䂀等. 金山湖 闸坝型水体表层沉积物重金属分布特征及生态风险评价. 环境科学, 2014, 35(11): 4127-4134.]

[14] Chu JY, Zhang JP, Zhou XH et al. Distribution characteristics and ecological risk evaluation of heavy metals in riverside sediments of Zhenjiang Canal. Environmental Chemistry, 2015, 34(4):763-771. [ 储金宇, 张金萍, 周晓红等. 镇江市 古运河河岸沉积物重金属分布特征及潜在生态风险评价. 环境化学, 2015, 34(4): 763-771.]

[15] Meena NK, Prakasam M, Bhushan R et al. Last-five-decade heavy metal pollution records from the Rewalsar Lake, Himachal Pradesh, India. Environmental Earth Sciences, 2017, 76(1): 39.

[16] Chen XK, Zhang HJ, Gu JG et al. Characteristics of sediment heavy metal pollution in three water supply reservoirs in Huizhou, Guangdong Province of South China. Chinese Journal of Applied Ecology, 2012, (5) : 1254-1262. [ 陈修康, 张 华俊, 顾继光等. 惠州市 3 座供水水库沉积物重金属污染特征. 应用生态学报, 2012, (5): 1254-1262.]

[17] Liu C, Shao SG, Fan CX et al. Pollution status and risk assessment of heavy metal in the sediment of thesevere polluted confluence area of Lake Chaohu. China Environmental Science, 2014, 34(4): 1031-1037. [刘成, 邵世光, 范成新等. 巢湖重污染汇流湾区沉积物重金属污染特征及风险评价. 中国环境科学, 2014, 34(4): 1031-1037.]

[18] Chen CX, Jiang X, Zhan YZ et al. Speciation distribution and potential ecological risk assessment of heavy metals in sediments of Taihu Lake. China Environmental Science, 2011, 31(11): 1842-1848. [陈春霄, 姜霞, 战玉柱等. 太湖表层 沉积物中重金属形态分布及其潜在生态风险分析. 中国环境科学, 2011, 31(11)：1842-1848.]

[19] Mao ZG, Gu XH, Lu XM et al. Pollution distribution and potential ecological risk assessment of heavy metals in sediments from the different eastern dredging regions of lake taihu. Environmental Science, 2014, 35(1): 186-193. [毛志刚, 谷孝 鸿, 陆小明等. 太湖东部不同类型湖区疏浚后沉积物重金属污染及潜在生态风险评价. 环境科学, 2014, 35(1): 186-193.]

[20] Kong M, Dong ZL, Chao JY et al. Bioavailability and ecological risk assessment of heavy metals in surface sediments of Lake Chaohu. China Environmental Science, 2015, 35(4): 1223-1229. [孔明, 董增林, 晁建顷等. 巢湖表层沉积物 重金属生物有效性与生态风险评价. 中国环境科学, 2015, 35(4) : 1223-1229.]

[21] Liu Y, Zhu YR, Wu FC et al. Pollution characteristics and ecological risk assessment of heavy metals in sediments of Dianchi Lake. Ecology and Environmental Sciences, 2014, 23(7): 1181-1186. [刘勇, 朱元荣, 吴丰昌等. 滇池沉积物中 重金属污染特征及其生态风险评估. 生态环境学报, 2014, 23(7): 1181-1186.]

[22] Zhang J, Wang SQ, Xie Y et al. Distribution and pollution character of heavy metals in the surface sediments of Liao River. Environmental Science, 2008, 29(9): 2413-2418. [张婧, 王淑秋, 谢琰等. 辽河水系表层沉积物中重金属分布 及污染特征研究. 环境科学, 2008, 29(9): 2413-2418.]

[23] Liu L, Xiong DQ, Gao XH et al. Characteristics of heavy metals contamination and distribution insurficial sediment of Haihe River and the adjacent sea area. Marine Environmental Science, 2006, 25(2): 40-44. [刘俐, 熊代群, 高新华等. 海河及邻近海域表层沉积物重金属污染及其分布特征. 海洋环境科学, 2006, 25(2): 40-44.]

[24] Liu ZT, Li CH, Zhang GY. Application of principal component analysis to the distributions of heavy metals in the water of lakes and reservoirs in Yunnan Province. Research of Environmental Sciences, 2010, 23(4): 459-466. [刘总堂, 李春 海, 章钢娅. 运用主成分分析法研究云南湖库水体中重金属分布. 环境科学研究, 2010, 23(4) : 459-466.]

[25] Lei P, Zhang H, Shan BQ. Analysis of heavy metals pollution and ecological risk assessment in the sediments from the representative river mouths and tributaries of the danjiangkou reservoir. Resources and Environment in the Yangtze Basin, 2013, 22(1) : 110-117. [ 雷沛, 张洪, 单保庆. 丹江口水库典型库湾及支流沉积物重金属污染分析及生态风险评 价. 长江流域资源与环境, 2013, 22(1): 110-117.]

[26] Xiong J, Wang F, Mei PS et al. Ecological risk assessment of heavy metal pollution in soils from the fluctuation belt of xiangxiriver in the three gorges reservoir. Research of Environmental Sciences, 2011, 24(11): 1318-1324. [熊俊, 王飞, 梅朋森等. 三峡库区香溪河消落区土壤重金属生态风险评价. 环境科学研究, 2011, 24(11): 1318-1324.]

[27] Liu LQ, Wei SQ, Jiang T. Distribution of soil heavy metals from water-level-fluctuating zone in Three-Gorge Reservoir area and their evaluation of potential ecological risk. China Environmental Science, 2011, 31(7) : 1204-1211. [刘丽琼, 魏世 
强, 江蹈. 三峡库区消落带土壤重金属分布特征及潜在风险评价. 中国环境科学, 2011, 31(7): 1204-1211.]

[28] Zhang S, Li LL, Zhang Y et al. Health risk assessment of heavy metals in water body of the Three Gorges Reservoir before and after the water level reached 135 meters. Environmental Pollution \& Control, 2006, 28(11): 865-867. [张晟, 黎莉 莉, 张勇等. 三峡水库 $135 \mathrm{~m}$ 蓄水前后水体重金属环境健康风险评价. 环境污染与防治, 2006, 28 (11): 865-867.]

[29] Shang LY, Sun RH, Ji YH et al. Risk assessment on heavy metals in sediments of rivers flowing into Miyun Reservoir.Environmental Science \& Technology, 2011, 34(S2) : 344-348. [尚林源, 孙然好, 汲玉河等. 密云水库人库河流沉积物 重金属的风险评价. 环境科学与技术, 2011, 34(S2) : 344-348.]

[30] Liu H. Research on key technology of flood control forecast and early warning for small and medium-sized reservoirs. Yellow River, 2015, 37(7) : 37-40. [刘恒. 中小型水库防洪减灾预报预警关键技术研究. 人民黄河, 2015, 37(7): 37-40.]

[31] Zhu XL, Chen H, Li YF. Key design points for danger control and reinforcement of drainage culverts under dam of small and medium reservoirs wen Fuyong. Yangtze River, 2011, 42(9): 57-60. [ 朱晓玲, 陈皓, 李玉芬. 中小型水库坝下排 水涵管除险加固设计要点. 人民长江, $2011,42(9): 57-60$.

[32] Jiang QM, Hou W, Gu JG et al. Nutritional status and population characteristics of Cyanobacteria in small and medium sized reservoirs in Guangzhou, southern China. Ecology and Environmental Sciences, 2010, 19(10) : 2461-2467. [江启 明, 侯伟, 顾继光等. 广州市典型中小型水库营养状态与蓝藻种群特征. 生态环境学报, 2010, 19(10): 2461-2467. ]

[33] Pekey H, Karakas D, Ayberk S et al. Ecological risk assessment using trace elements from surface sediments of Izmit Bay ( Northeastern Marmara Sea) Turkey. Marine Pollution Bulletin, 2004, 48(9/10) : 946-953.

[34] Muller G. Index of geoaccumulation in sediments of the Rhine River. Geo Journal, 1969, 2(3) : 108-118.

[35] Håkanson L. An ecological risk index for aquatic pollution control: A sedimentological approach. Water Research, 1980, 14(8) : 975-1001.

[36] Chernoff H. The use of faces to represent points in k-dimensional space graphically. Journal of the American Statistical Association, 1973, 68(342) : 361-368.

[37] Zhou CS, Zou SZ, Li LJ et al. Comparision of evaluation methods for soil heavy metals contamination. Earth and Environment, 2015, 43(6) : 709-713. [周长松, 邹胜章, 李录娟等. 几种土壤重金属污染评价方法的对比. 地球与环境, $2015, \mathbf{4 3}(6): 709-713$.]

[38] Guo XX, Liu CQ, Zhu ZZ et al. Evaluation methods for soil heavy metals contamination: A review. Chinese Journal of E$\operatorname{colog} y, 2011,30(5)$ : 889-896. [郭笑笑, 刘丛强, 朱兆洲等. 土壤重金属污染评价方法. 生态学杂志, 2011,30 (5) : 889-896.]

[39] Praveena SM, Ahmed A, Radojevic M et al. Heavy metals in mangrove surface sediment of Mengkabong lagoon, Sabah: Multivariate and geo-accumulation index approaches. International Journal of Environmental Research, 2008, 2 (2) : 139-148.

[40] Wang QH, Dong YX, Zhou GH et al. Soil geochemical baseline and environmental background values of agricultural regions in Zhejiang province. Journal of Ecology and Rural Environment, 2007, 23(2): 81-88. [汪庆华, 董岩翔, 周国华 等. 浙江省土壤地球化学基准值与环境背景值. 生态与农村环境学报, 2007, 23(2):81-88.]

[41] Christophoridis C, Dedepsidis D, Fytianos K. Occurrence and distribution of selected heavy metals in the surface sediments of Thermaikos Gulf, N. Greece. Assessment using pollution indicators. Journal of Hazardous Materials, 2009, 168(2/3): 1082-1091.

[42] Meena NK, Prakasam M, Bhushan R et al. Last-five-decade heavy metal pollution records from the Rewalsar Lake, Himachal Pradesh, India. Environmental Earth Sciences, 2017, 76(1) : 39.

[43] Sutherland RA. Bed sediment-associated trace metals in an urban stream, Oahu, Hawaii. Environmental Geology, 2000, 39(6) : 611-627.

[44] Liu Y, Yue LL, Li JC. Evaluation of heavy metal contamination and its potential ecological risk to the soil in Taiyuan, China. Acta Scientiae Circumstantiae, 2011, (6) : 1285-1293. [刘勇, 岳玲玲, 李晋昌. 太原市土壤重金属污染及其 潜在生态风险评价. 环境科学学报, 2011, (6) : 1285-1293.]

[45] Xu L, Wang T, Wang J et al. Occurrence, speciation and transportation of heavy metals in 9 coastal rivers from watershed 
of Laizhou Bay, China. Chemosphere, 2017, 173: 61-68.

[46] Liu WX, Li XD. Distribution of heavy metals among various phases in Shenzhen Bay. Acta Scientiae Circumstantiae, 2002, 22(3) : 305-309. [刘文新, 李向东. 深圳湾水域中重金属在不同相间的分布特征. 环境科学学报, 2002, 22(3): 305-309.]

[47] Liu JH, Wang WH, Peng A. Pollution and sources of hg in top soil in two district ofbeijing city. Acta Scientiae Circumstantiae , 1998, 18(3) : 109-114. [刘俊华, 王文华, 彭安. 北京市二个主要工业区永污染及其来源的初步研究. 环境 科学学报, $1998,18(3): 109-114$. ]

[48] Gray CW, Mclaren RG, Roberts A et al. The effect of long-term phosphaticfertiliser applications on the amounts and forms of cadmium in soils underpasture in New Zealand. Nutrient Cycling in Agroecosystems, 1999, 54(3) : 267-277.

[49] Facchinelli A, Sacchi E, Mallen L. Multivariate statistical and GIS-based approach to identify heavy metal sources in soils. Environmental Pollution, 2001, 114(3) : 313-324.

[50] Zhao SM, Wang DW, Li XM et al. Assessment on heavy metals pollution in surface sediments of Dianchi Lake and its estuaries. Ecology and Environmental Sciences, 2014, 33(2): 276-285. [赵世民, 王道玮, 李晓铭等. 滇池及其河口沉 积物中重金属污染评价. 环境化学, 2014, 33(2): 276-285.] 